\title{
A Case of Fibrolipoma of the Nasal Septum
}

\author{
Yeong Wook Jeong, Joo Yeon Kim, Dong Young Kim, and Jae Hwan Kwon 1 (D) \\ Department of Otolaryngology-Head and Neck Surgery, Kosin University College of Medicine, Busan, Korea
}

\section{비중격에 발생한 섬유 지방종 1예}

정영욱 · 김주연 · 김동영 · 권재환

고신대학교 의과대학 이비인후과학교실

\author{
Received April 24, 2020 \\ Revised June 26, 2020 \\ Accepted July 6, 2020 \\ Address for correspondence \\ Jae Hwan Kwon, MD, PhD \\ Department of Otolaryngology- \\ Head and Neck Surgery, \\ Kosin University \\ College of Medicine, \\ 262 Gamcheon-ro, Seo-gu, \\ Busan 49267, Korea \\ Tel +82-51-990-6247 \\ Fax +82-51-245-8539 \\ E-mail entkwon@hanmail.net
}

\begin{abstract}
Lipoma is the most common benign neoplasm in adults. While it is commonly found in the neck, trunk, and extremities, it is extremely rare in the nasal cavity, paranasal sinus, or nasal septum. To our knowledge, there have been only a few cases of septal lipomas reported in the English literature. A 32-year-old woman visited Kosin University Hospital complaining of left nasal congestion and throat discomfort. Upon nasal endoscopy examination and $\mathrm{CT}$, we found a polypoid mass of $2.7 \times 1.5 \mathrm{~cm}$ with an elongated neck occupying a region left of the nasopharyngeal to the oropharyngeal cavity. The mass was completely removed via endoscopic endonasal surgery under general anesthesia and was identified as a fibrolipoma in the histopathological examination. We report a case of a successfully treated fibrolipoma originating from the posterior margin of the nasal septum.
\end{abstract}

Korean J Otorhinolaryngol-Head Neck Surg 2020;63(10):475-8

\section{Introduction}

Lipoma is a benign neoplasm which grows slowly, which occurs in the neck, trunk, and extremities, but rarely found in the nasal sinus and nasal septum. ${ }^{1}$ Until now, lipomas of the nasal septum were reported in one case in Korea, ${ }^{2}$ and three cases (including fibrolipoma, which is a subtype of lipomas) abroad. ${ }^{1,3,4)}$ We found a mass in the nasal septum who presented with intermittent nasal obstruction. The mass was completely removed by endoscopic endonasal surgery, and histological examination revealed a fibrolipoma. We report this case with a review of the literature.

This is an Open Access article distributed under the terms of the Creative Commons Attribution Non-Commercial License (https://creativecommons.org/licenses/by-nc/4.0) which permits unrestricted non-commercial use, distribution, and reproduction in any medium, provided the original work is properly cited.

\section{Case}

Thirty-two-year-old woman visited us with complaints of intermittent nasal obstruction and throat discomfort. She had no other symptoms nor underlying disease. An endoscopic examination revealed an elongated round mass covered by normal nasal mucosa originated from the posterior edge of the nasal septum that extended to the nasopharynx (Fig. 1A and B). Computed tomography (CT) revealed a $2.7 \times 1.5 \mathrm{~cm}-$ sized, low-density, polypoid mass originating from the posterior part of the nasal septum with an elongated neck occupying the left nasopharyngeal to oropharyngeal cavity (Fig. 1C). The nasal septum slightly deviated to the right side and concha bullosa in the left middle turbinate was observed (Fig. 1D).

We planned to conduct an endoscopic endonasal mass excision surgery. After the induction of general anesthesia, 1:1000 epinephrine mixed with lidocaine was injected into both septal mucosa. After correcting the deviated nasal sep- 

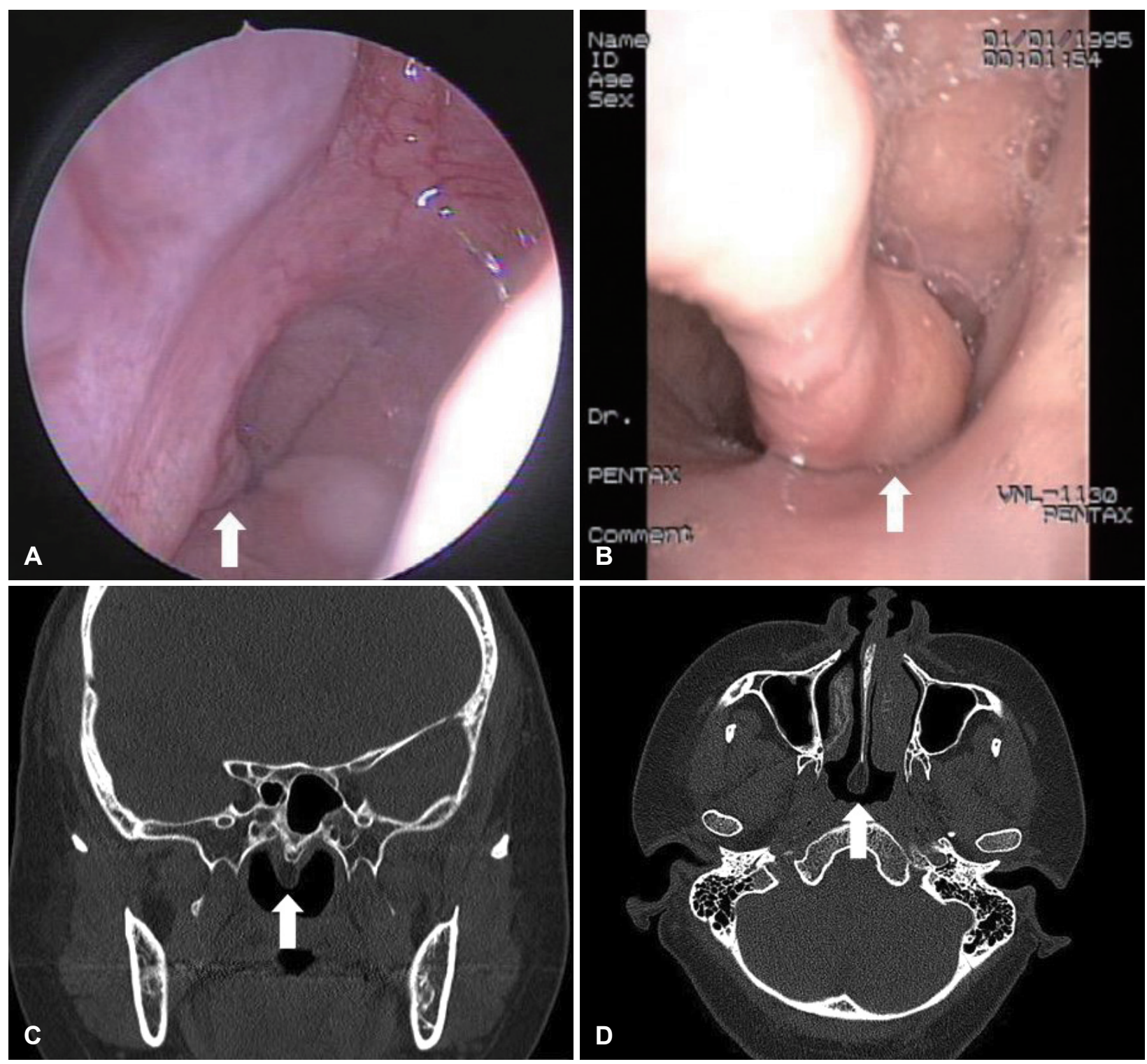

Fig. 1. Endoscopic and radiologic examination of the patient's nasal cavity. (A) The endoscopic view shows a mass lesion on the left posterior part of the nasal septum. (B) It occupies $1 / 3$ of the nasopharynx. The mass originates from the posterior part of the nasal septum inferolaterally. (C) Coronal and (D) Axial CT scan. The low-density mass is abutted to the left posterior part of the nasal septum. Nasal mass attached to posterior part of the nasal septum (arrow).

tum, we located the mass in the nasopharynx which measured approximately $3.0 \times 1.0 \mathrm{~cm}$. We completely removed the mass and a silastic sheet was placed on both of the nasal septum and fixed using vicryl 4-0. On histopathological examination, the mass was approximately $2.7 \times 1.5 \mathrm{~cm}$ and consisted of homogeneously-distributed yellow tissue which had a clear margin with the surrounding tissue (Fig. 2A). Microscopically, mature adipose tissue cells were found in the subepithelium; no atypical cells were found (Fig. 2B), and the surface of the mass was covered with ciliated pseudostratified columnar epithelium cells which appeared to be normal respiratory epi- thelium (Fig. 2C). The final histological diagnosis was fibrolipoma. Postoperatively, the mucosa of the posterior nasal septum recovered to normal, and the patient was followed for more than 6 months without any recurrence (Fig. 3).

\section{Discussion}

Lipoma is a slowly growing benign tumor and consists of mature fat cells, which usually occurs in the neck, trunk, or limbs. However, lipomas originated from the parasinus and nasal septum are extremely rare. Because there is a paucity 

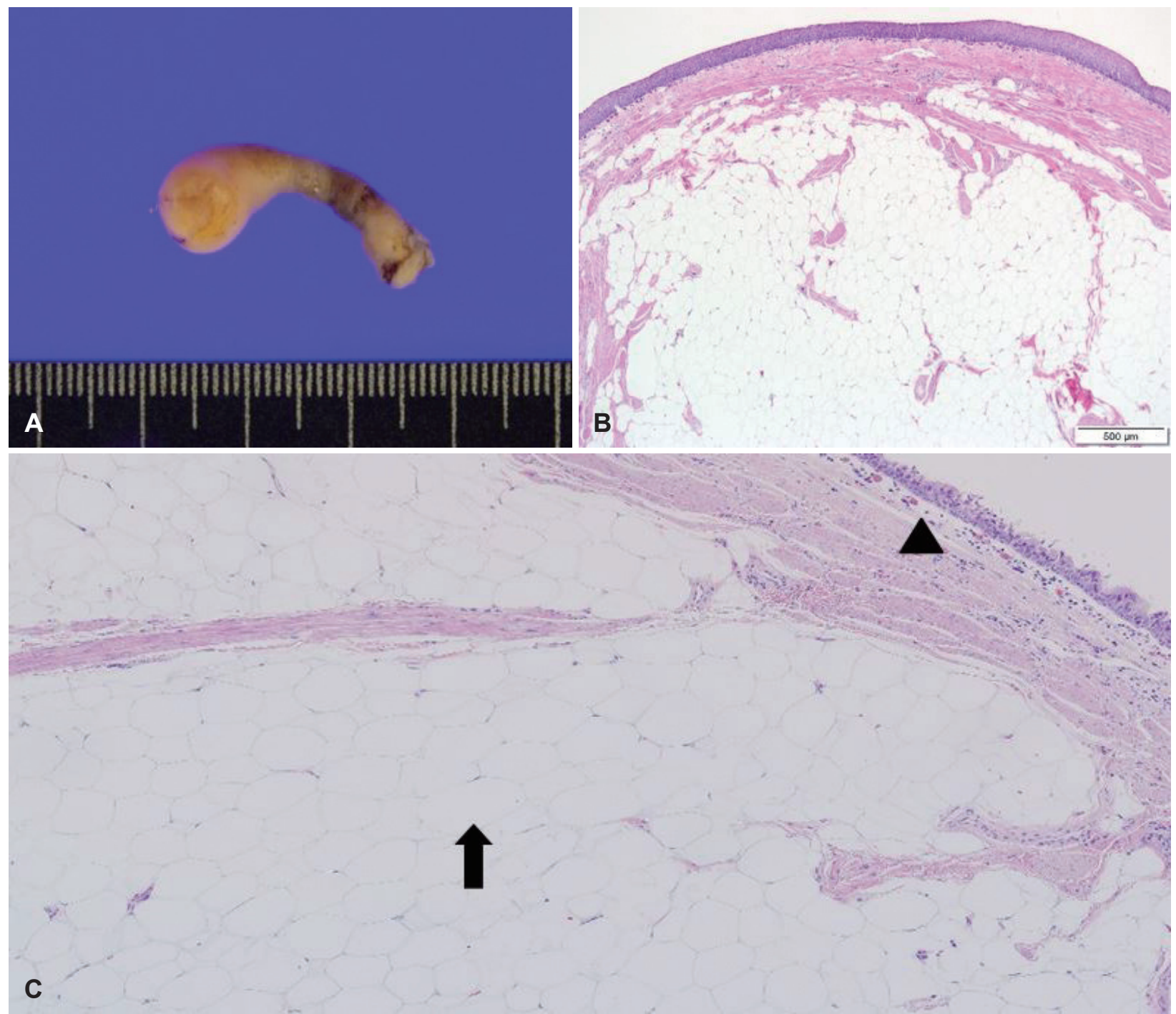

Fig. 2. Gross and histopathological finding of the tumor. (A) The tumor is a well defined solid yellow mass. (B) Histopathological finding. Mature adipose tissues are proliferating in the subepithelial area. There is no atypical cells which present evidence of malignancy (H\&E stain, $\times 40$ ). (C) Ciliated pseudostratified columnar epithelium (respiratory epithelium) (arrowhead), subepithelial mature adipose tissue $(H \& E$ stain, $\times 200)$ (arrow). H\&E stain: hematoxylin and eosin staining.

of adipose in the parasinus area, the tissues are less likely to progress to lipomas. ${ }^{3,4}$ The lipomas remain asymptomatic clinically, but once they grow in size, which can cause discomfort as they compress surrounding structures. ${ }^{5}$ Lipomas originated from the nasal septum result in symptoms such as unilateral nasal obstruction, facial edema, tenderness, rhinorrhea and epistaxis. ${ }^{2}$

The reported benign tumors found in the nasal septum include schwannoma, pleomorphic adenoma, chondroma, hemangioma, teratoma, leiomyoma, papilloma, and lipoma. ${ }^{2)} \mathrm{Li}-$ pomas are classified according to their subtypes, which include simple lipomas, fibrolipomas, myxoid lipomas, angiolipomas, spindle cell lipomas, pleomorphic lipomas, angiomyolipomas, myelolipomas, and lipoblastomatosis. ${ }^{6,7)}$ The microscopic findings in this case revealed that the surface of the mass was covered with ciliated pseudostratified columnar epithelium cells which appeared to be normal respiratory epithelium, and mature adipose tissue cells were found in the subepithelium, that revealed fibrolipoma. The causes of lipomas have not been evaluated yet. It is known to be caused by the remaining adipose tissues during progress or development of existing adipocytes. ${ }^{8)} 1 \%$ of fibrolipomas occur in the facial region, ${ }^{1)}$ and fibrolipomas that originated in the nasal septum reported in one adult ${ }^{1)}$ and one child ${ }^{9)}$ worldwide. In addition, lipomas in the parasinus can occur very rarely in infants as part of a syndrome that includes symptoms involving the 


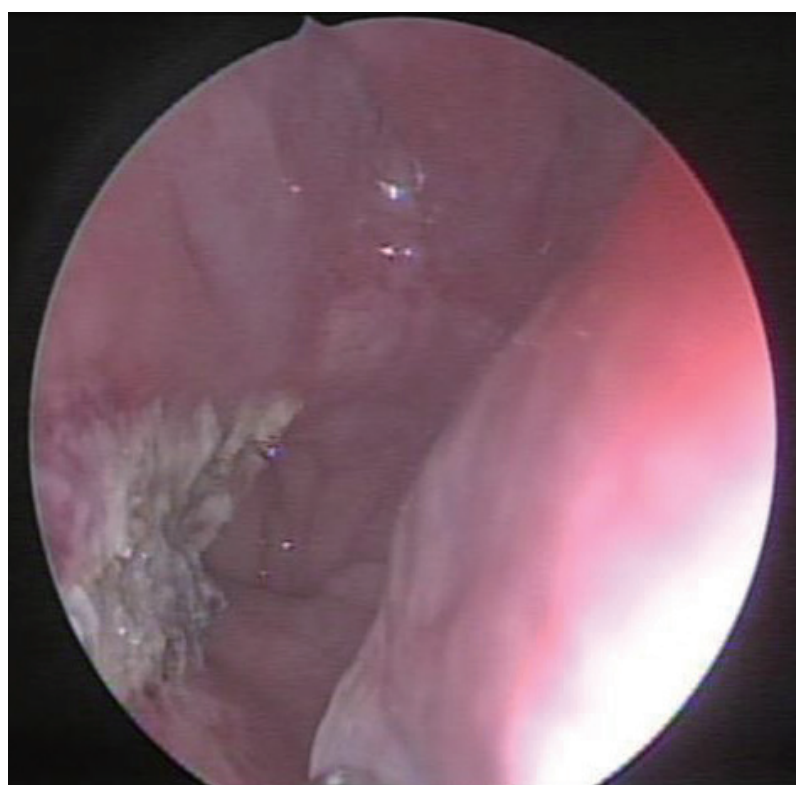

Fig. 3. The post-operative endoscopic view shows that the mass was completely removed.

brain. ${ }^{10)}$ Fibrolipomas are mostly diagnosed as benign, and progression to liposarcoma is extremely rare. ${ }^{1)}$

Preoperative radiologic examination is essential to differentiate between other tumors and lipomas and to know the exact extension of the mass. ${ }^{4)}$ In particular, CT and magnetic resonance imaging (MRI) help diagnose lipoma and discover its extension and characteristics. The radiologic characteristics of lipomas are as follows: low-density findings on CT, high signal intensity on T1-weighted MRI, and low signal intensity on T2-weighted MRI. ${ }^{4)}$ In this case, the CT images showed low-density polypoid findings.

Treatment for facial lipomas is the same as for those which occur in other parts of the body: complete surgical resection. ${ }^{79}$ In this case, the mass and the posterior margin of the nasal septum were completely removed with a $1 \mathrm{~cm}$ resection margin. We endeavored to preserve as much of septal mucosa as possible, and the mass with capsule was well separated from the mucosa of the septum. Blood vessels which were exposed during surgery were cauterized by the bipolar cauterizer.

Lipomas can relapse several years after they have been completely removed, but local recurrence rate is less than $5 \%$.
Therefore, long-term follow-up must be recommended. ${ }^{11,12)}$

We report a case of fibrolipoma originating from the posterior part of the nasal septum with an elongated neck occupying the left nasopharyngeal to oropharyngeal cavity, which was successfully removed by an endoscopic approach, and we also report a review of the literature.

\section{Acknowledgments}

None.

\section{Author Contribution}

Conceptualization: Jae Hwan Kwon. Data curation: Jung Young, Wook Jeong. Resources: Young Wook Jeong. Supervision: Jae Hwan Kwon. Visualization: Dong Young Kim. Writing — original draft: Joo Yeon Kim. Writing — review \& editing: Jae Hwan Kwon.

\section{ORCID}

Jae Hwan Kwon https://orcid.org/0000-0002-3260-6969

\section{REFERENCES}

1) Ozturk M, Ila K, Kara A, Iseri M. Fibrolipoma of the nasal septum; report of the first case. J Otolaryngol Head Neck Surg 2013;42(1):11.

2) Cho JH, Shim DB, Hong SC, Kim JK. Lipoma on the nasal septum. Korean J Otolaryngol-Head Neck Surg 2006;49(5):568-70

3) Preece JM, Kearns DB, Wickersham JK, Grace AR, Bailey CM. Nasal lipoma. J Laryngol Otol 1988;102(11):1044-6.

4) Takasaki K, Yano H, Hayashi T, Kobayashi T. Nasal lipoma. J Laryngol Otol 2000;114(3):218-20.

5) Acquaviva G, Varakliotis T, Badia S, Casorati F, Eibenstein A, Bellocchi G. Lipoma of piriform sinus: A case report and review of the literature. Case Rep Otolaryngol 2016;2016:2521583.

6) Moon TH, Lee DJ, Lee SJ, Jung PS. A case of lipoma of epiglottis. Korean J Otorhinolaryngol-Head Neck Surg 2009;52(3):270-2.

7) Ahn SK, Jeon SY, Kim JP, Baek SM. A case of lipoma of the tonsil. Korean J Otolaryngol-Head Neck Surg 2002;45(8):831-3.

8) Furlong MA, Fanburg-Smith JC, Childers EL. Lipoma of the oral and maxillofacial region: Site and subclassification of 125 cases. Oral Surg Oral Med Oral Pathol Oral Radiol Endod 2004;98(4): 441-50.

9) Funai MNS, Risola CF, Gomes LM, Pinto JA. Fibrolipoma of the nasal septum: An unusual pediatric case. Int J Pediatr Otorhinolaryngol Extra 2015;10(3):37-9.

10) Hollis LJ, Bailey CM, Albert DM, Hosni A. Nasal lipomas presenting as part of a syndromic diagnosis. J Laryngol Otol 1996; 110(3):269-71.

11) Derin AT, Yaprak N. Lipomas: Review and evaluation of the literature. Clin Surg 2017;2:1615.

12) De Vincentiis M, Greco A, Mascelli A, Soldo P, Zambetti G. Lipoma of the larynx: A case report. Acta Otorhinolaryngol Ital 2010;30(1): 58-63. 